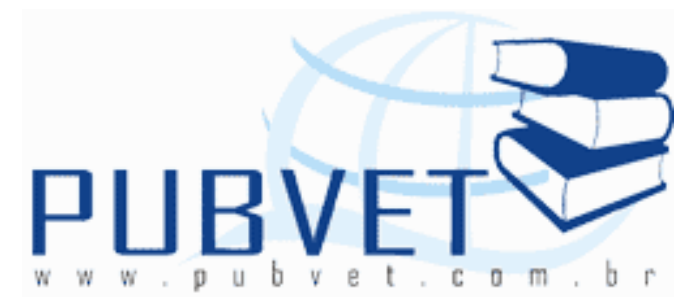

PUBVET, Publicações em Medicina Veterinária e Zootecnia.

Disponível em: <https://doi.org/10.31533/pubvet.v02n10a381>.

\title{
A visão homeopática do tratamento e prevenção do câncer em pequenos animais
}

\section{Daniela Franco Lopes}

Médica Veterinária Injectcenter, Mestre em Engenharia Biomédica

\section{Resumo}

O envelhecimento e a obesidade representam fatores de risco bem conhecidos para que haja o desenvolvimento do câncer. Os tratamentos tem como objetivo a redução progressiva geral do tumor, um prolongamento do intervalo livre de doença e melhora na qualidade de vida através do alívio dos sinais associados ao câncer. O fato é que mesmo que cientificamente tenhamos evoluído muito nos últimos 10 anos através do conhecimento da Biologia do Cancer, os próximos anos serão de vital importância para melhorarmos a terapêutica, devido ao grande numero de casos, ainda estamos longe de erradicar o câncer. Esta revisão tem como objetivo proporcionar uma informação concisa ao medico veterinário, alertando e esclarecendo as diversas formas de Prevenção na fase pré-miasma segundo Hahnemann, utilizando conhecimento das doenças crônicas e associando as novas 
possibilidades Terapêuticas e de Diagnostico. Concluímos que não são suficientes tratamentos e sistemas diagnósticos sofisticados que não mudaram as estatísticas do câncer, é necessário traçar programas de prevenção contínua e precoce mesmo em pacientes cirúrgicos.

Palavra-chave: Homeopatia Injetável, Câncer, Diagnóstico, Prevenção.

\section{Introdução}

A mais antiga evidência de câncer foi verificada no ano 8000 a.C., raramente observado nos fósseis o Osteosarcoma (1: 5000 casos), é o resultado de mutação genética que sempre existiu segundo a paleopatologista Eggers (USP). Por volta do ano 1600 a.C., foram encontrados relatos de câncer nos Papiros egípcios e na Índia, relacionados à ingestão de sementes cancerígenas ${ }^{1}$.

Hipocrates utilizou pela primeira vez o termo "Carcinos" para denominar a doença, pois os gregos o chamavam de Caranguejo porque as projeções e vasos o faziam lembrar o crustáceo. No ano 130-200 d.C., Galeno considerado a maior autoridade da época, foi referenciado dizendo que a doença era incurável e nada teríamos a fazer. Posteriormente em 1531, Michelangelo fez a obra "La notte" demonstrando a existência de uma deformidade no seio de sua musa, subentendendo ser câncer ${ }^{\mathbf{1}}$.

Hahnemann em Organon da arte de curar descreve nos parágrafos 80 e 171 que o câncer assim como os neoplasmas, são formas de Psora devendo ser tratados com antipsóricos, portanto, necessária a utilização de diversos medicamentos antipsóricos seguidamente, de maneira que cada um seja administrado conforme a persistência dos sintomas até que chegue a cura ${ }^{2}$. 
Nos últimos anos, os cães passaram de simples animais domésticos, utilizados muitas vezes como instrumentos de trabalho nas mais diferentes atribuições, a membros importantes de muitas famílias. Essa transformação foi vista inicialmente nos países desenvolvidos, mas gradualmente espalhou-se por várias partes do mundo. A longevidade é um efeito atribuído a melhor nutrição, uso imunizante preventivos e um aumento da atenção global aos animais que adquiriram status de membro da família ${ }^{7,15}$.

\section{Câncer e Homeopatia}

O câncer só começa a existir em um terreno, em um organismo preparado para aceitá-lo. Nos seres humanos, são pessoas que por muitos anos não respeitaram as suas próprias células, abusaram do fumo, do sal, das gorduras saturadas, dos carboidratos refinados, dos alimentos enlatados, dos embutidos e dos defumados, se contaminaram com metais tóxicos e se impregnaram com o medo, a inveja e a depressão. Com os animais, seus donos fazem esta escolha, pois no reino animal a dieta e estilo de vida seria menos agressivo. As causas do câncer são múltiplas, o tratamento também deve ser múltiplo ${ }^{3}$. Os Miasmas são formas reacionais orgânicas conhecidas também por DIÁTESE, em que o doente encontra sua predisposição mórbida que se torna um obstáculo a cura.

Sicose: expulsão de secreções (Gonorréia) e tumorações provenientes de infecções genitais venéreas (TVT, Doença do Figo), vacinas e inoculação de substâncias estranhas, Hipertrofia do ego (THUYA);

Sífilis: sintomas mentais e físicos de destruição, vingança, ódio, deficiências fisiológicas, Cancro venéreo (MERCURIUS);

Psora: são alterações mentais, como medos, angustias Hipersensibilidade a som e sensações, o contagio é imediato, mas as erupções levam alguns dias (SULFUR, HEPAR, SEPIA); 
Em Doenças Crônicas de Hahnemann, o miasma Psora foi notificado como doença crônica mais antiga que se conhece. Há 3400 anos ela foi responsável pelo Fogo de Santo Antonio, Lepra no sec.XIII, uma erupção de pele no século XV conhecida por Sarna, que é uma doença longa, mais contagiosa e destrutiva de todos os miasmas. Foi suprimida ilusoriamente por banhos, sudoríferos e misturas repugnantes que diminuíam a força vital, promovendo a cronicidade dos sintomas impedindo a cura. Segundo Hahnemann esta perturbação cutânea já existia no corpo antes como doença interna, como predisposição e a penetração do agente ocorre através dos nervos periféricos. Após alguns anos, se não curada, ocasiona nestes indivíduos submetidos a desvios de dieta, resfriamentos (úmido e frio), esforço físico, sustos, desgostos, contrariedades sofreriam de tumores, supurações crônicas, histerias, doenças mentais, hemorragias, asma sufocante ${ }^{4}$.

\section{Pesquisas Oncológicas}

Informações oncologicas atuais revelam que o câncer é um aglomerado de doenças neoplásicas (tendências patológicas), relacionadas a raças e famílias de animais aos mapas genéticos, onde se verificou que os cães são os que mais se assemelham aos humanos, devido à presença do Gene BRCA -1 canino que tem $80 \%$ de homologia com o câncer de mama humano, portanto utilizado como modelo experimental em pesquisas. Sabe-se que a célula tumoral tem menos cromossomos (59) do que as normais (78) e que todos os tumores apresentam alterações no gene TP53 que programa apoptose e diferencia tumores benignos ${ }^{5}$.

As cinco vias de ocorrência de carcinogenese são: Química, Física, Biológica, Hereditária e Passiva5. Embriologicamente existe uma semelhança do câncer com embrião, pois são originados de uma célula, onde os tumores 
malignos originam-se no mesoderma e os benignos na endoderme ou ectoderme.

Pesquisas homeopáticas publicadas com Viscum album utilizados em humanos desde o século XIX ${ }^{43}$ e recentemente em 2007 no Brasil, um estudo in vivo ${ }^{6} \mathrm{e}$ em in vitro verificaram a citotoxidade do homeopático Viscum album Injectcenter em células Caco-2 7,39.

\section{Diagnostico}

Os programas de detecção de câncer são amplamente usados e considerados bem sucedidos para muitos tipos de câncer em seres humanos, porém, na medicina veterinária as medidas de rotina para detecção do câncer ainda não foram amplamente desenvolvidas e aplicadas, em parte pela falta de consenso sobre as doenças, vital para a triagem e também pela dificuldade inerente ao desenvolvimento de programas que satisfaçam o sucesso descrito anteriormente ${ }^{8}$.

De acordo com a Veterinary Cancer Society, os sintomas clássicos de câncer em animais incluem edemas ou inchaços anormais que persistem e crescem, ferimentos que não cicatrizam, há perda de peso e apetite, sangramentos e secreções, febre, odor desagradável, dificuldade para comer ou deglutir, intolerância a exercícios e perda da resistência, claudicação ou rigidez, dificuldade para respirar, urinar ou defecar ${ }^{8}$.

Os exames clínico-laboratoriais como hemograma completo, urina tipo I, dosagem nível sérico de cálcio, dosagem de fosfatase alcalina (marcador tumoral que ajuda no diagnóstico de metástase óssea e hepática), dosagem de glicoproteina sérica alfa-1-acida, desidrogenase láctica (DHL), perfil de uréia, creatinina, TGO, TGP e fosfatase alcalina são indispensáveis ao iniciarmos um 
mapeamento de câncer na primeira consulta. Não devemos dispensar à boa anamnese, conhecendo o histórico familiar, levando em conta a predisposição racial (BIRCHARD; SHERDING, 1998; PARDINI, 2003), e as tendências miasmáticas ${ }^{11}$.

Em termos de medida, o tumor somente ficará visível ao atingir $1 \mathrm{~cm}^{3}$ ou $10^{9}$, portanto, as terapias são iniciadas quando o tumor já tomou grandes proporções, implicando em permitir que ocorra a Angiogenese quando atingirem $2 \mathrm{~mm}^{3}$, facilitando metástases ${ }^{8}$. Gatas com tumores mamários menores que $2 \mathrm{~cm}$, a sobrevida media é de 3 anos, ao passo que se estiverem superiores a $3 \mathrm{~cm}$, a sobrevida cai para 4-9 anos. Já as cadelas com tumores mamários menores que $2 \mathrm{~cm}$ a sobrevida é 511 dias, se for superior a $3 \mathrm{~cm}$ a sobrevida será 164 dias ${ }^{8}$.Portanto a sobrevida do paciente esta diretamente ligado ao volume tumoral, ao utilizar citostáticos pré operatórios que reduzem de $10^{9}(1 \mathrm{~cm}=1$ milhao de células $)$ para $10^{8}$ ou $10^{6} 12$.

Os chamados marcadores tumorais ainda pouco utilizados na Medicina Veterinária poderiam ser de grande valia no auxílio ao diagnostico precoce e no prognostico, pois estas moléculas ocorrem no sangue ou tecidos quando o câncer esta presente. Um marcador ideal para a Medicina Veterinária seria aquele que através de um exame de sangue simples fornecesse um resultado positivo, apenas em portadores de câncer e que correlacionasse o estagio em que se encontra a doença. Além da resposta ao tratamento, também pudesse ser facilmente mensurável, todavia sabe-se que ainda não existe nenhum marcador especifico ${ }^{5}$. Podemos citar alguns dos marcadores tumorais utilizados em pequena escala na Medicina Veterinária, como a Telomerase, uma enzima que adiciona novas seqüências telomericas a extremidade do DNA, sendo esta atividade enzimática apenas verificada em tecidos anormais ${ }^{5}$. Dentre eles a Imunohistoquimica constitui um método bastante sensível para identificar marcadores tumorais, a saber: ki67, Agnors e PCNA (marcadores de proliferação celular usado em mama), p53 (gene 
supressor tumoral), $\operatorname{Pr}$ e $\mathrm{Er}^{13}$. O teste de acido sialico sérico total (TSA) ${ }^{5}$ pouco utilizados.

O PCR (reação em cadeia da polimerase), atualmente é usado para identificar expansão clonal de linfócitos e plasmocitos neoplásicos, em cães identificam-se focos sistêmicos de neoplasia linfóide ${ }^{5}$. O Pet Scan é um teste genético que é utilizado na identificação da predisposição ao câncer, verificando o consumo de glicose celular, pois sendo elevado o consumo indica presença de tumor ${ }^{5}$. A Citogenética molecular pode ser usada com a finalidade de diagnostico do estagio clínico em seres humanos ${ }^{14}$.

A Citologia aspirativa de linfonodos ou de massas tumorais tem sido largamente usado por veterinários, sendo eficaz no diagnostico. A Biopsia Histopatológica por remoção de fragmento tecidual local através de corte cirúrgico ou punch é uma maneira fácil e segura, requerendo apenas posterior conservação em solução de formol tamponado a $10 \%$.

O Diagnóstico por imagem como a Radiografia Torácica, informam as condições metastáticas pulmonares, preferindo-se a posição a ventro dorsal e lateral direita. A Ultrassonografia identifica lesões parenquimatosas intra abdominais, a qual o Raio-X não pode detectar, sendo pouco invasivo e confiável ${ }^{5,9}$.

Podemos ainda, contar com exames mais sofisticados como Ressonância Magnética (NIRs), a Tomografia Computadorizada, Cintilografia Nuclear, usada para tireóide e metástases ósseas ${ }^{15}$.

Recentemente a Espectroscopia Raman Dispersiva (ERD), um método óptico, realizada in vitro e in vivo, como no câncer ${ }^{16,17}$ foi utilizado pela primeira vez em um experimento na área veterinária ${ }^{7}$. O laser de Raman (ERD), através da interação da luz com tecido, fornece a impressão digital de uma substância cuja característica molecular pode ser determinada 18, que permitem a caracterização genética, morfológica e bioquímica do 
câncer 7. As vantagens são a eficácia e a rapidez da verificação da compatibilidade terapêutica entre a droga e o paciente, o que permite mudanças estratégicas durante a terapia, com análise em tempo real, sem necessidade de procedimentos invasivos e com a vantagem de custos reduzidos ${ }^{19}$. A Técnica de ERD revelou ser um método valioso e sensível para a detecção da mudança na atividade mitocondrial das células, os resultados são dados em tempo real de exame7. Os Prognósticos de pacientes cancerosos são baseados em evidencias clinico - laboratoriais e biopsias repetidas, que requerem anestesia geral, custo alto e estresse na expectativa do laudo, que são dispensados com esta técnica?.

\section{Terapias Oncológicas Disponíveis}

As terapias atualmente disponíveis são a Cirurgia, Radioterapia, Quimioterapia, Imunoterapia, Modificadores da resposta biológica, Hipertermia, Crioterapia, Fototerapia, Fotoquimioterapia, Termoquimioterapia, Alternativos (Homeopatia, Acupuntura, Floral Quântico) 6, 7, 11, 15, 20, 39. Qualquer terapia alopática escolhida tem por finalidade atuar na inibição do crescimento celular em diversas fases de divisão celular, incluindo células sadias. A maioria se trata de químicos e radiação provenientes de metais pesados que fiquem impregnadas na célula promovendo a oxidação e morte celular e deixando resíduos maléficos as células saudáveis, comprometendo a Homeostase e levando o individuo a morte $e^{4,6,20}$.

Verificamos problemas com a escolha terapêutica, no que diz respeito a treinamento adequado e uma pratica clinica para utilização das drogas disponíveis na Medicina Veterinária. Os efeitos colaterais promovidos não são bem identificados e tratados por profissionais que não tenham especialidade oncológica. Os médicos veterinários ainda não possuem conhecimento oncologico para estabelecer metas de tratamentos que se 
adéqüem ao tipo de câncer e ao tipo de vida que os proprietários desejam que seus animais sejam submetidos. A relação proprietário-animal constitui base fundamental na escolha da terapia, pois o melhor tratamento para um tumor não constitui necessariamente o melhor tratamento para determinado paciente ou o melhor tratamento do ponto de vista do proprietário, deve-se considerar também o nível de desempenho de Karnovsky ${ }^{15}$.

Ainda existe uma rejeição aos métodos terapêuticos tidos como Alternativos por grande parte dos médicos veterinários. A falta de conhecimentos em biologia celular para uma programação racional que vise evitar recidivas, metástases e controle tumoral como em humanos, depende do diagnóstico inicial e do tumor não ser perturbado por terapias e exames invasivos anteriormente mal sucedidos ${ }^{9}$. Só assim então conseguiremos como os médicos pensar em programas de Prevenção em massa, esclarecendo proprietários e médicos veterinários, de que podemos melhorar muito e reduzir a casuística da doença com novos estudos.

As terapias chamadas Modificadores Biológicos são substancias sintéticas ou naturais que alteram a relação hospedeiro-tumor, resultando em um efeito antitumoral como o Viscum album 6,42, um vegetal semiparasita utilizado largamente na Europa no tratamento e prevenção de vários tumores desde meados do séc.XIX ${ }^{43}$. Junto aos Oligoelementos ${ }^{21}$, tem por finalidade mudar padrões de resposta celular, induzindo a apoptose por citotoxidade, promovendo um aumento gradual e permanente da imunidade, equilíbrio da Homeostase celular, além da preservação integral da saúde do paciente evitando efeitos indesejáveis dos químicos tanto ao veterinário como ao paciente ${ }^{7,39}$. O que garante 0 efeito destes produtos é a presença de monócitos, linfócitos, plasmocitos e células T-linfociticas nos tumores e em pacientes imunocomprometidos, a documentação da remissão de câncer pelo seu uso comparada a rara remissão sem qualquer outra forma de terapia além da melhora clinica verificada ${ }^{6}$. Outros critérios são utilizados, como a avaliação da resposta do tumor aos tratamentos como a RC (Remissão completa), RP 
(redução parcial), DE (doença estável, redução menor 25\% diâmetro), DP (Doença progressiva, aumento maior que $25 \%$ diâmetro), são utilizados por veterinários ${ }^{15}$.

\section{MODELOS DE TRATAMENTOS HOMEOPATICOS PARA CANCER}

Inicialmente, identificar a fase pre-miasmatica que começa com lesão dos sentimentos, ora apresentados anteriormente após estudo e interpretação dos miasmas descritos no Organon ${ }^{2}$. Posteriormente, a escolha do Simillimun individual de cada paciente, indicado por Hahnemann, acompanhado da limpeza miasmática com a seqüência Thuya, Luesinum, Calcaria fluorica, Carcinosinum 4, 20, 22,23. A Baryta carbonica e o Scirrhinum são indicados nos estágios pré-câncer nas potencias altas cada um ${ }^{20}$. Um estudo americano aconselha-se uma drenagem Renal e Hepática com homeopáticos Bardana e Taraxacum de dia, seguidos de Berberis e Kreosotum de noite, que podem auxiliar a eliminação de toxinas e radicais livres que o organismo acumulou durante o período pré- miasmático em que o stress, o medo excessivo e permanente, a raiva colerizada ao ser dissipada altera as membranas celulares, desestabilizando a Homeostase, promovendo a oxidação celular além do acumulo de cortisol endógeno. Podemos utilizar ainda uma combinação de Carqueja / Bardana / Barbatimão / Cavalinha para auxiliar e eliminar as toxinas dos quimioterápicos convencionais, auxiliar a digestão e melhorar os efeitos colaterais dos quimioterápicos $23,24,25,26,27,31$.

A terapia Viscum album Injectcenter conjugada a outros homeopáticos injetáveis, está sendo utilizada desde 2004 é um agente modificador biológico, vem demonstrando ser eficaz no tratamento, controle e manutenção da boa qualidade de vida em vários pacientes caninos e felinos, tendo sua atividade positiva verificado em Osteosarcoma de Radio, Hemangiosarcoma de baço, Carcinoma epitelial ${ }^{6}$, além do adenocarcinoma e colon in vitro ${ }^{7,42}$. 
O tratamento pode ainda ser complementado com medicações homeopáticas orais que possuem similitude ou tropismo com determinados órgãos, medicamentos de ação local que promovam conforto ao paciente reduzindo a dor, septicemia, hemorragias, aumentando a biodisponibilidade de elementos essenciais a boa Homeostase, perdida ao longo da doença 6, 20,34.

\section{Epidemiologia e Prevenção}

O câncer é a segunda doença em ocorrência do planeta, felizmente $75 \%$ dos casos em seres humanos e animais que poderiam ser previnidos, mas não o são. Na Ásia a incidência do câncer de mama, de próstata e de colon é bem menor que na América do Norte, possivelmente pelo alto consumo de isoflavonas. Estudos em animais corroborados por evidências epidemiológicas mostram forte relação entre o consumo de isoflavonas e o baixo índice de câncer ${ }^{21}$.

Os itens exibidos a seguir são de vital importância para evitar o aparecimento e prevenir recidivas da doenças:

Devemos começar com a mudança dos padrões cerebrais (dono, ambiente e paciente), diminuição do stress, medo excessivo, raiva e psiquismos desde inicio da vida 20,23, mudar o estilo de vida, principalmente os que se referem à dieta, iniciar programas de prevenção do câncer nas raças propensas $^{11}$;

Instituição de terapias homeopáticas contínuas após tratamento cirúrgico e/ou químico, mesmo nos casos de diagnóstico maligno, pois poderão manter a qualidade de vida ${ }^{8,11}$;

Instituir programas de castração precoce até um ano idade nas fêmeas, evitando assim uso prolongado e indiscriminado de hormônios ${ }^{8,9}$; 
Fazer programas de saúde bucal, estimulando escovação e extração de tártaro;

Prevenção da Obesidade precoce, explicando aos proprietários que animal gordo não é sinônimo de saúde ${ }^{5,8,9}$;

Programa de desverminação continua principalmente nos cancerosos ${ }^{23}$,

Evitar uso de químicos supressores (Ectoparasiticidas, derivados de petróleo) que apenas escondem a Psora ${ }^{4}$.

\section{Conclusão}

Com este artigo verificamos a importância de conhecer melhor a Biologia do câncer e de começar a utilizar tão logo as ferramentas da Biologia molecular e da engenharia biomédica, que permitem o conhecimento da genética e das proteínas desta doença. Não bastam termos recursos terapêuticos avançados e permitir que a incidência do câncer seja um dos maiores relatados historia da medicina veterinária. É necessário traçar melhores planos de diagnostico, terapia e principalmente prevenção, lançando programas universitários e comunitários, nas clinicas que esclareçam melhor os veterinários e posteriormente os proprietários de como podemos enfrentar com otimismo e tranqüilidade esta patologia complexa.

O Veterinário homeopata entende que para fornecer a Energia Vital perdida devido à doença, é através da regulação da Homeostase, onde a célula mantém o equilíbrio celular, não significa fornecer glicose ou ativar a gliconeogenese no ciclo de Krebs. Tratar o paciente num todo como corpo e mente, restabelecendo os padrões mentais modificados por sentimentos de raiva, medo, stress, contrariedade, insegurança, perda, possessividade e ciúmes, tais como nos humanos, promovendo a transformação dos padrões 
energéticos cristalizados pela cronicidade, praticando a Teoria de Doenças Crônicas descrita por Hahnemann no sec.XVII.

\section{Bibliografia}

01. AAPCAN, História do câncer. Disponível em http://www.aapcan.org.br/sobre cancer.php. Acesso em 19/08/2008.

2. MORENO, JA., O Organon da arte de curar de Samuel Hahnemann, 3.a edição. Ed. Hip. Hahnemanniana. Belo Horizonte, 2006.

3. FELIPPE, Jj. Melanoma, Biblioteca do Cancer. Disponível em http://www.medicinacomplementar.com.br/tema300707.asp. Acesso em 19/08/2008.

4. HAHNEMANN, SF.Doenças Cronicas, Fundamento Teoricos, vol.1, tradução de Edméa M. Vilela e Izao C.Soares, Museu de Homeopatia Abrahao Brickmann, 1a ed., Ed.Paulista, 2007.

5. ROSENTHAL, RC. Segredos em Oncologia veterinária. Porto Alegre: Artmed, 2004.

6. LOPES, DF; CARVALHO, AC; SIBATA, MN. Estudo de casos clínicos oncológicos n.6, 2007. Disponível em:<http: //www.pubvet.com.br/texto.php?id=68>.

7. LOPES, DF. Viscum album citotoxicity in Caco-2cells (in vitro) analyzed by Dispersive Raman Spectroscopy, Thesis Abstract, International Journal of High Dilution Research, v.7, issue 23, p.7778, June 2008, (C2008 GIRI.

8. HOSKINS, JD. Geriatria e Gerontologia do cão e gato, 2a Ed., Rocca, 2004.

9. BIRCHARD, SJ; SHERDING, RG. Manual Saunders Clinica de Pequenos Animais, Ed. Rocca, 1998.

10. PARDINI, H. Manual de exames, Instituto de Patologia Clinica, 2003/2004.

11. ROY, RK. Homoepathy in Cancer Treatment, $1^{\text {a }}$ Ed, Ed.Bjain Published, N.Delhi, Índia, 2003.

12. MACHETTI, AH; MARAND, HRC; CAVALINNI, ME. Concepts of Tumoral Kinetics Applied to Chemoteraphy of breast cancer, Medicina (Ribeirão Preto), 40(2): 213-22 2007.

13. ATLEN, D; CHEVALLIER, B.; SHENG, RG. Tamoxifen for the treatment of metastatic inflammatory breast carcinoma. American Journal of Clinical Oncology, v.18, pg.74-77, 1995.

14. SLATTER, D. Manual de Cirurgia de Pequenos Animais, 2a Ed., Ed.Manole, vol.2, 1998.

15. NELSON, RW.; COUTO, CG. Medicina Interna de Pequenos Animais, $2^{a}$ Ed., Ed.Guanabara Koogan, 2001. 
Lopes, D.F. A visão homeopática do tratamento e prevenção do câncer em pequenos animais. PUBVET, Londrina, V. 2, N. 39, Art\# 381, Out1, 2008.

16. CHOWDARY, MVP; KALYAN KUMAR, K; THAKUR, K; ANAND, A; KURIEN, J; MURALI KRISHNA, C; MATHEW S. Discrimination of normal and malignant mucosal tissues of the colon by Raman Spectroscopy. Photomed Laser Surg., v.25, n.4, p.269-274, 2007.

17. NUNES, L.O; MARTIN, A.A; SILVEIRA JR, L; ZAMPIERI, M. FT-Raman Spectroscopy study for skin cancer diagnosis. Spectroscopy Int J., v.17, n.2-3, p.597-602, 2003.

18. LORINCZ, A.; HADDAD, D.; NAIK, R.; FUNG, A.; CAO, A.; MANDA, P.; PANDYA, A.; AUNER, G.; RABAH, R.; LANGERBURG, SE; KLEIN, MD, Raman Spectroscopy for Neoplasic Tissue Diferetiation : a pilot study. Jounal of Pediatric Surgery,v.39, n-6, p.953-956, 2004.

19. STONE, N; KENDALL, C; SMITH, J; CROW, P; BARR, H. Raman spectroscopy for identification of epithelial cancers. Faraday Discussions, v.126, p.141-157, 2004.

20. RAMAKRISHNAN, AU; COUTHER, C. A Homoepathic Approach to Cancer, Nigth House Publishing, 2001.

21.FELIPPE, J]. Dieta Inteligente Journal of Biomolecular Medicine \& Free Radicals. 6(3): 8595, 2000.

22. BARBOSA, E. Cancerinismo e Grafologia, prevenção precoce do câncer, SBHC, RJ, 1a Ed., 2003.

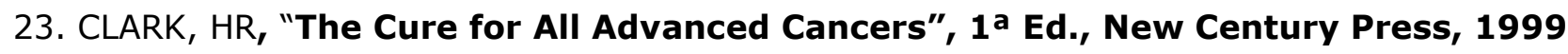

24. DORCSI, M. Homeopatia, vol.3 Especialização, Ed. Roca, 1982.

25. MACHADO, I. Guia Homeopático, 6a Ed., Ed.Robe, 2000.

26. DUFILHO, R. Ficha de Matéria Medica Homeopático, o Piano Homeopático, Ed.Andrei, 2000.

27. VOISON, H. Manual de Matéria Medica Homeopática para o Clinico Homeopata, Ed. Andrei, 2a Ed., 1987.

28. MEDIO, H. Veterinaria Homeopatica, Kier Editorial, 2004.

29. HAMILTON, D. Homoepathic Care for Cats and Dogs, North Atlantic Books, 1999.

30. DAY, C. The Homoepathic treatment of small animals, Saffron Walden, 1998.

31. QUIQUANDON, H. Matiére Medicale, Homeópathie Vétérinaire, Biotherapies, Paris: Point Vétérinaire, 1983.

32. VANNIER, L; PORRIER, J. Tratado de Matéria Medica Homeopática, Ed.Andrei, 9a Ed., 1998.

33. TETAU, M. Matéria Medica Homeopática, Alvos Específicos, Ed.Andrei, 2005.

34. BOERICKE, W. - Materia Medica With Repertory. Calcutá:Roy Publishing House, 1968.

35. MORENO, JA, Kent e Egito, Miasmas - Segundo Hahnemann, 26a Ed. Hipocrática Hahnemanniana. Belo Horizonte, 2002.

36. $N A T U R A L C A N C E R T R E A T M E N T S$ THAT WORK, disponível em Http://www.naturalcancertreatments.com 
Lopes, D.F. A visão homeopática do tratamento e prevenção do câncer em pequenos animais. PUBVET, Londrina, V. 2, N. 39, Art\#381, Out1, 2008.

37. STOCK, W.Homeopathic Injectables, Importance of the parenteral administration of homeopathic and athroposophic remedies, 2002. Disponível em: <http://www.echamp.org/pdf all/homeopathic inject.pdf >

38. LEFEBVRE, GNF; BONAMIN, LB; OLIVEIRA, CM. Tratamento do Tumor venéreo transmissível (TVT) utilizando Viscum album em associação a quimioterapia, Revista Clinica Veterinária, n.70, p.78-86, 2007.

39. GHELMAN, R. Ação do Viscum album sobre a prenhes da rata albina (Rattus norvegicus albinus, Rodentia, Mammalia): estudo morfológico e radiológico. 2003. $123 \mathrm{f}$. Tese (Doutorado) - Curso de Medicina Veterinária, Universidade Federal de São Paulo, São Paulo, 2003.

40. BLOSTIN, R. ROLE OF Viscum album in Feline Fibrosarcoma: First Results of a French study, Arquivos da escola de Homeopatia, Cultura Homeopática, p.38, 16/2006.

41. MURPHY, C. Iscador. Mistletoe and câncer therapy, Panacea Wellness Guide, 2001.

42. BELLAVITE, P; SIgNORINI, A. The Emerging Science of Homeopathy. Ed.North Atlantic Books, 2002.

43.CARVALHO, AC; LOPES, DF; SIBATA, MN.O uso do Viscum album em quarto séculos, APHAnais do 40 Congresso Paulista de História da Medicina, 2008. 